This is a preprint version of the paper. An edited and corrected version of this paper as published is available to view at https://rdcu.be/ch1tl

\title{
Educational technology: what it is and how it works
}

Jon Dron<jond@athabascau.ca>, Faculty of Science \& Technology, Athabasca University, Athabasca, Alberta, Canada

ORCID ID: https://orcid.org/0000-0002-6521-7302

\section{Abstract}

This theoretical paper elucidates the nature of educational technology and, in the process, sheds light on a number of phenomena in educational systems, from the no-significantdifference phenomenon to the singular lack of replication in studies of educational technologies. Its central thesis is that we are not just users of technologies but coparticipants in them. Our participant roles may range from pressing power switches to designing digital learning systems to performing calculations in our heads. Some technologies may demand our participation only in order to enact fixed, predesigned orchestrations correctly. Other technologies leave gaps that we can or must fill with novel orchestrations, that we may perform more or less well. Most are a mix of the two, and the mix varies according to context, participant, and use. This participative orchestration is highly distributed: in educational systems, coparticipants include the learner, the teacher, and many others, from textbook authors to LMS programmers, as well as the tools and methods they use and create. From this 
perspective, all learners and teachers are educational technologists. The technologies of education are seen to be deeply, fundamentally, and irreducibly human, complex, situated and social in their constitution, their form, and their purpose, and as ungeneralizable in their effects as the choice of paintbrush is to the production of great art.

Keywords

Technology, distributed cognition, coparticipation, Educational technology, participation, design

Declarations

Funding : Athabasca University

Acknowledgements: I give thanks to Terry Anderson and Gerald Ardito for their insightful feedback and suggestions to improve this work. 


\section{Introduction}

This paper presents an argument that education - the giving and receiving of systematic instruction, the process of facilitating learning, constituted from countless methods, tools, and structures, operated by teachers and many others - may usefully be seen as a technological phenomenon; that all educators are thus educational technologists (albeit that their choices of technology may vary); and that this has some very far reaching consequences for research and practice, explaining some hitherto puzzling phenomena, and challenging some of the fundamental beliefs held by many educators and researchers in education. Before exploring these conclusions, however, we must better understand the nature of technologies, and the various different roles we (collectively and individually) play in their enactment and instantiation.

\section{The nature of technologies}

The term 'technology' is, as Nye (2006, p.15) puts it, an 'annoyingly vague abstraction,' with many fuzzy, shifting, evolving, inconsistent, and sometimes contradictory meanings. There is widespread agreement that technologies do things for us, or help us to achieve our purposes (e.g. Turkle \& Papert, 1992 ; Nye, 2006; Arthur, 2009)). There is also common recognition that, as Franklin (2014, p.172) puts it, they are "the way we do things", implying regularized structuring and organization of objects, concepts, and so on in order to achieve those purposes. Part of the problem, though, is that technology can be both something that we do and something that has been done, often simultaneously. When we write we are using the 
technology of writing, doing the technology of writing and creating a technology of writing, all at once. Kelly (2010) describes technology as "not a thing but a verb" but it is - at least - both. As Franklin (1999, p.6) asks, "How does one speak about something that is both fish and water, means as well as end?" One very promising answer is provided by W.Brian Arthur (2009, p.51), who describes technology as "the orchestration of phenomena for some purpose". This definition elegantly encompasses three of the most central aspects of all technologies: that they make use of stuff (real or imagined, mental or physical, designed or existing in the natural world); that the stuff is organized by someone; and that this organized stuff is used for something. The definition works equally well whether we treat technology as a means or an end, a thing or a verb. To orchestrate is to intentionally bring different things - actions, tools, methods, processes, etc - together in an organized form, and an orchestration is the result of doing so.

\subsection{Assembly and technological evolution}

Arthur's definition is particularly compelling because it is tightly coupled with his fundamental insight that many of the orchestrated phenomena in any given technology assembly are orchestrated by other technologies - nuts and bolts, rules of grammar, software compilers, and so on - building on and incorporating those that already exist. Technologies thus tend to evolve towards greater complexity. As Kauffman $(2019$, p. 134) puts it, “...new technologies grow out of the technologies that now exist. The actual flows into its adjacent possible." Virtually all technologies are joint undertakings, involving innumerable humans, past and present (Read, 1958), all of whom orchestrated phenomena to some purpose, and whose artefacts and 
methods contribute materially - if not necessarily directly - to our own tools, knowledge and skills, in an unbroken chain leading back to flint axes, the dawn of language, and perhaps beyond.

Though specific technologies may perish, the types that they represent are seldom if ever fully displaced (Kelly, 2010). Thus, technologies evolve and the technological ecosystem constantly expands and diversifies. Technological evolution differs from natural evolution inasmuch as it occurs through combinations of existing technologies rather than genetic adaptations (Arthur, 2009). Furthermore, and unlike naturally evolved species, technologies do not have to work straight away; they can be brought back from the dead; they can be assembled with others that existed in different times or at a geographical distance; success criteria may be more than mere survival; and they can be created with foresight of future conditions (Page, 2011). However, the dynamics of the process - including survival of the fittest - are essentially similar. A large and complex technology like education is the result of layer upon layer of other mutually constitutive and affective technologies that both combine and compete. When we build new technologies, from LMSs (learning management systems) to lesson plans, they are built upon and from others.

Technologies may be partially or wholly instantiated by physical (including virtual) machines, and/or by people. Human-enacted technologies like organizational processes, or methods of design and manufacture, are as much technologies as cars or factories (Arthur, 2009; Kelly, 2010), a fact that is already recognized in many widely used definitions of educational 
technology, such as those of the AECT (Lakhana, 2014). Some technologies - such as mental arithmetic or meditation - may be instantiated wholly in our minds.

\subsection{Educational technologies}

It follows that pedagogies - by which I mean methods, models, or principles of teaching - are as much technologies as computers, and may be instantiated by people and/or embedded in physical tools and structures. Like all technologies, pedagogies are themselves assemblies that orchestrate various phenomena, notably including assumptions about how people learn. Almost all common pedagogical methods are assemblies that are incomplete without other technologies such as classrooms, courses, or, at the very least, words and sentences to complete them. There are no naked pedagogies.

I propose that an educational technology, or learning technology, may tentatively be defined as one that, deliberately or not, includes pedagogies among the technologies that it orchestrates. While a subset of educational technologies are designed and sold for the purpose - learning management systems, textbooks, electronic whiteboards, courses, etc. - almost any technology (from a factory to a word processor) can, when combined with appropriate pedagogies and other technologies, be used to support or engender learning. Neither learner nor designer need be aware of, let alone intend this. For example, the maker of a toy car may not think of it as educational, and the child playing with it may not be planning to learn from it, but the imaginative games that they play can underpin a powerful process of learning. 
All teachers use technologies, and technologies mediate all formal education. There may be a superset of what might be described as educational technologies that, arguably, are not made to support learning: summative exams, for instance, student record systems, regulations relating to behaviour, or class scheduling tools. However, when used within an educational system the intent of which is to teach, these do in fact contribute to learning, whether positively or not. Just as we would seldom speak of screws as computing technologies - despite the fact that screws are necessary parts of most computers - so we should be wary of thinking of the parts of an educational technology system as educational technologies in their own right. They become so when they affect learning in an educational system. Timetables, for instance, make a huge impact on learning: they set a time to learn that may or may not be ideal, a duration that may or may not be appropriate, an expectation of compliance, a signal to focus on learning, and much more that may, depending on the situation, be positive or negative in its effects. The point that matters is that they are part of the technology of learning, whether for good or not, and that they embed profound assumptions about learning, and about how it should be engendered.

\subsection{Faustian bargains}

Though most technologies solve problems, most new technologies create new problems to solve (Brand, 2000, loc.189). Postman (2011, p. 192), calls this the "Faustian Bargain" of technology, a kind of Monkey's Paw effect in which a wished-for result leads to unwanted sideeffects. This occurs in part because as Olson (2013, p. 233) observes, "negative entropy in one part of the system creates entropy elsewhere." Whenever we create order, we also create 
disorder and, as we perturb a system, so it seeks a new equilibrium. To a large extent, though, it occurs because creating a technology brings new phenomena into the world, that are fundamentally unpredictable in advance (Kauffman, 2019). We usually respond to the Faustian bargain by creating counter-technologies. Unfortunately, as Dubos $(1969, \mathrm{p} .8)$ puts it, "developing counter technologies to correct the new kinds of damage constantly being created by technological innovations is a policy of despair." Many technologies in educational systems, from exam regulations to user roles in an LMS are counter-technologies that are designed to curb the unwanted effects of others we have created.

\subsection{Not science}

Many definitions of 'technology' refer to it as the application of science ("Technology"' n.d). This is false. Scientific theories and discoveries may increase the available phenomena for orchestration, and thus some technologies do indeed apply science. However, it is more accurate to say that science is applied technology (including theories and models, which are correctly described as tools in scientific literature) than to say that technology is applied science. Many technologies do not rely on scientific knowledge at all. There are, for example, technologies of prayer (Franklin, 1999), or of poetry (Kelly, 2010). Language itself (Kelly, 2010; Rheingold, 2012; Ridley, 2010; Wilson, 2012; Changizi, 2013), and all the arts, are technologies, as are their products. Many educational technologies, from exam rubrics to methods of teaching, may similarly have little or nothing to do with science, at least in their design and execution, though they may use some phenomena that have been discovered through science, and might be researched using at least quasi-scientific methods. 


\subsection{Never neutral}

Technologies are seldom if ever morally neutral. Apart from those explicitly designed to do harm or good, they may enable better ways to dominate or subdue our fellow humans, being what Boyd (1996) describes as 'dominative' or what Franklin (1999) calls 'prescriptive'. Equally, they can be liberative (Boyd, 1996) or holistic (Franklin, 1999), sustainably supporting personal and cultural growth and creativity. When viewed in context as part of a broader system, all technologies embody values and beliefs (Bijker et al, 1989). As technologies, pedagogies can and do oppress (Freire, 1972) as much as they may liberate (Dewey, 1916).

Technologies are often seen as 'other'. Few of us understand more than a little of how many of them work, from institutional bureaucracies to computer software. However, this sense of alienation is not just due to opacity. As Max Frisch (1994, p. 178) puts it, technologies are "the knack of so arranging the world that we don't have to experience it." Aristotle saw writing, for instance, as two steps removed from experience (Micham, 1997, p.329), and Socrates (Plato, 360BCE) bemoaned the semblance of memory it provides. However, technologies lie deep within us, and human life would be unimaginable without them. The words and syntax of language are as much technological inventions as writing, and are fundamental to our personal and collective intelligence (Heyes, 2018). We are inescapably part-technology (Haraway, 2013) but, equally and just as meaningfully, our technologies are part-us. Similarly, most human intelligence is at least partly artificial - in the sense of not existing in the world until we invented it - from technological inventions like formal logical or mathematical methods, to the composition of music in our heads. Arguably, our technological nature may extend to some 
basic mechanisms of cognition that are rarely seen as technological in character such as selective social learning, imitation, and mindreading (Heyes, 2018).

Learning, in contrast, is not a technology - it is a natural phenomenon done by babies fresh from the womb, most organisms on the planet and, arguably, many other systems up to and including ecosystems or even, as Brand suggests, the homes we live in (Brand, 1997) - but almost all the means by which it is intentionally accomplished by human beings, and a good number of its products (such as language, theories, remembered poems, etc) are.

\section{Participation and plasticity}

We are not just users but participants in the orchestration of technologies, with active roles to play in achieving their ends, from trivially simple actions (e.g. pressing a button) to inordinately complex activities (e.g. writing a paper about technologies and education).

Sometimes we must participate as cogs, becoming a part of a technology's predetermined orchestration. I have previously described these as hard technologies (Dron, 2013), not (as some use the term) because of their personal or social effects on us (e.g. Baldwin and Brand, 1978; Norman, 1993), nor (as others prefer) because of their physical constitution (e.g. McDonough and Kahn, 1996), but because of the rigidity of their behaviour. For example, activities like winding mechanical watches, reciting scriptures, or answering objective quiz questions must be performed more or less exactly as required in a predetermined order for the technology to work correctly. Some - for instance, implementing mathematical algorithms may demand great skill, but it is a skill that can be perfected: we can be flawless cogs. As and in 
assemblies, they may have other roles: a mechanical watch, say, may be a status symbol, a source of aesthetic pleasure, a souvenir, and much more but, as a timepiece, our role in both winding it and interpreting the positions of its hands is fixed. Creative watch-winding will, at best, void the warranty.

Many technologies - including watches - embed such orchestrations in the form of physical (including virtual) machines. These are often the machines that (in assembly with other technologies) extend our capabilities far beyond what humans could do alone, from the trillions of calculations a second performed by computers to journeys into space, as well as many more mundane but deeply important roles like providing clean drinking water, tracking time, or moving ourselves and our material goods at high velocity.

Conversely, we equally often participate in technologies as active and creative orchestrators of phenomena. Teaching methods, musical instruments, and computers demand that we provide additional processes and techniques (idiosyncratic ways of doing things) in order for them to do anything useful at all. I have described these as soft technologies (Dron, 2013), due to their innate plasticity. The precise uses and forms of soft technologies are seldom, if ever, fully predictable: a violin does not dictate precisely how it should be played nor what music it makes, but it does affect both, in its affordances and constraints, thanks to the things that it does preorchestrate. This in turn affects how and with what it can be orchestrated. But there are countless ways to play the violin that have never been tried, in all its long history, and most of the process of doing so involves idiosyncratic, unformalizable tacit knowledge (Polanyi, 1966. 
We may try to copy and learn from another's technique, but our individual technique is always our own.

Softness is not so much an observable aspect of a given technology as an absence. There are gaps made possible by hard technologies that may or, often, that must be filled. Humans add methods, techniques, and (sometimes) other tools to make them complete. A pencil, say, is inherently incomplete without further orchestration of technologies like writing, drawing, or paper, though these roles barely scratch the surface of all its possible uses. A screwdriver, does have a hard and distinct role in driving screws correctly, in which we must play our part with some precision, but offers countless and other adjacent possibles that may be filled: prising the lid off a can of paint, for instance, or committing murder. The full range of a screwdriver's possibilities is unprestatable (Kauffman, 2008) - we cannot in principle or practice know them all in advance. Some of its indefinitely many uses may have recognizable names - a pointer, a weapon, a stirrer, a prop, a lever, etc. - but many may not. It is this unprestatability that underpins what Bijker (1987) describes as 'interpretive flexibility'. Bijker is concerned with the perspectives, beliefs, environment and social conditions under which technologies may be adapted and appropriated, but what makes it possible is the relative softness inherent or latent within the physical, conceptual, or virtual artefacts themselves.

Because they require us to make more choices - to orchestrate phenomena in order to fill the gaps they leave - enacting softer technologies often requires creativity and skill. It takes time to gain expertise in using/participating in them but, in contrast to hard technologies, there is rarely if ever a point at which we can reliably claim to have perfected our skills. Adjacent 
possibilities are enabled, but not entailed by them (Kauffman, 2019), and each new actuality enables further possibilities, ad infinitum.

Harder technologies tend to provide efficiency, precision, and replicability, but at a cost of flexibility and adaptability. Softer technologies tend to offer creativity, flexibility, and resilience, but demand skill and effort. Soft is hard, hard is easy (Dron, 2013). This is the origin of the trade-off between efficiency and flexibility that challenges designers of all technologies, from teachers in classrooms to software architects to educational policy makers. It is also at least partly the basis for education's 'iron triangle' of access, cost, and quality (Daniel et al, 2009), where quality is (arguably) seen to depend upon soft (creative, skillful, and flexible) teacher engagement, thus increasing expense and limiting scalability.

\subsection{Assemblies that soften or harden}

Almost all technologies are assemblies of both soft and hard technologies, so extremes are vanishingly rare. All hard technologies were once soft to their creators and, once created, can nearly always be assembled with other technologies (soft or hard) and so become softer. Computers, for example, consist of nothing but hard, deterministic components but (at least to their programmers) form the basis of among the softest of technologies because the ways we could extend them, with software, hardware, and methods, are essentially infinite.

Equally, most if not all soft technologies contain at least some hardness. It would not be describable as a technology at all if there were not some consistent elements, be they natural or unnatural phenomena, or ways of orchestrating them. Even the softest of technologies can 
(notably when assembled with rules or embodied in machines) become harder. A pencil used to join the dots is harder than one used to doodle. Notice again, though, that it is not the pencil that has changed, but the use and the orchestration: it is that assembly that is the technology of interest, including the tacit knowledge and skills of the doodler, not the pencil.

Because their essence is replicability and precision, hard technologies can usually, at least in principle, be automated. Soft technologies cannot, because their potential uses are unprestatable. This is not to suggest that machines cannot surprise us, nor that they cannot imitate human creative processes: machines can produce remarkably human-like artworks, music, poetry, and prose. Chatbots have fooled students into thinking they are human, albeit in very limited domains (Goel et al., 2016). However, though generative and perhaps even original, such machines are not in control of the orchestration: they have no intentions beyond those programmed into them, so the use to which the orchestration is put (what makes it a technology) is not their own, but that of the creator and/or owner of the system. The range of phenomena they can orchestrate is limited to what their programmers built them to do or enabled them to learn. Automation can mimic soft technologies within a limited context but, at least for the foreseeable future, cannot create them.

Cooley, talks scathingly of technologies that automate and instead calls for those that informate (Cooley, 1987). However, automation hardens a technology only when it replaces a soft process, such as when we replace informal in-person questions with automated online quizzes. In such cases, we should at the very least be sceptical of the benefits, although I am cautiously in favour of the kind of automation that cleans our drinking water or that ensures our safety at 
road junctions. Automation can, though - and perhaps surprisingly - soften the overall assembly, offering greater freedom and diversity for the people who participate in it. This occurs if and only if it augments the original soft technology that it automates. Most smart whiteboards, for example, retain the softness of their dumb forebears, but supply further automated features, like state saving, that increase the adjacent possible. However, soft is hard: they are costlier, more complex, less reliable, and more difficult to learn. Like all technologies, what they add may come at more than a financial cost, especially when combined with other technologies such as mandates to use them. Moreover, the softness may be available but, unless people are aware of, empowered to, and capable of taking advantage of it, the system remains hard to them. For example, if a vehicle provides both manual and automatic gear shifting, the manual option is useless unless the operator knows how to use it. Equally, providing choices in an online learning tool is of little value if it is buried even a couple of menus down in a system that provides defaults. For instance, I discovered that $99.15 \%$ of over 6,000 courses on my institutional learning management system accepted its default landing page, even though, when informed of the option, over half of those surveyed expressed a desire to change it (Dron, 2006).

The softest of technologies may be hardened with imposed rules that replace human choice with predetermined decisions, regardless of automation. This is often the worst of both worlds: the technology is hard and inflexible, but it must be instantiated by fallible, fickle humans who are anything but. Rules are often used to harden otherwise soft technologies and thus to control and to dominate their participants. This may be done with the best of intents. For example, explicit or implicit rules that prevent everyone speaking at once, or that disallow 
assignment submissions after a fixed time, or that require proctored written exams, or that mandate attendance at lectures, are almost always intended for the good of all, or at least in a spirit of fairness. The costs, though, can be very high. Speaking for myself, as a teacher, I often really want my students to all 'speak' at once (in an online chat system), I want to give them as long as they need to learn and to excel, I would rather tear my own hair out than give them a proctored written exam, and the thought of mandating lecture attendance gives me visceral shivers. When I have encountered such rules I have either broken them or found ways to eliminate them at source. This is possible because, to me (often counter to the intent of their creators), they are soft. I have worked with many colleagues who have believed them to be much harder. Even then, the rules of assembly provide a way out. For example, a colleague who believed that he must offer proctored written exams, but who accepted the arguments against them, short circuited the system by making the exam a fun reflective commentary on work done within his (entirely project-based) course, with a couple of questions known to students in advance about what they did and how they did it (Huntrods \& Dron, 2017).

\subsection{Structural patterns}

Harder technologies usually play a larger structural role in the assembly than soft technologies, because they are less flexible and thus cannot as easily be changed. Like natural ecologies (O'Neill et al, 1986) and cities (Brand, 1997), the slower-changing elements affect the fasterchanging more than vice versa. Hard technologies cause path dependencies; paths that, once taken, exclude other paths. 
Unless hardened into structures, regulations, or machines, pedagogies are, at least to teachers, normally very soft technologies so they hardly ever come first in any learning design because there are harder technologies with which they must be assembled that are structurally more rigid.

Some constraint is good: boundaries are a prerequisite of creativity (Boden, 1995), without which there is nothing to push against or build upon. However, hard technologies may orchestrate phenomena counter-productively. A learning management system, for example, configured to only allow interaction within fixed length courses can inhibit many pedagogically valuable uses that leverage the connections between subjects or the continued growth of knowledge when the course is over (Dron, 2014). Many similarly hard technologies, like classrooms, courses, timetables, or grades - are so embedded that we fail to see them as anything other than natural parts of educational systems, but their effects are at least as substantial. The effect is amplified by many technologies with which they interlock regulations, policies, standards, and so on - that form webs of dependencies that are highly resilient to change.

\subsection{Perspectives}

What is soft for one person may often be hard for another. A rigid lesson plan, for example, may be very soft to the teacher that creates it but very hard for students who must learn from it. Though sharing obvious components these are different combinations of technologies, orchestrating different phenomena for different uses and, in assembly, should therefore not be treated as the same thing. This is true even when we have designed technologies ourselves. We 
may substantially control the process of creating presentation slides, for instance, but when they are used to provide a presentation, the path dependency we have created may henceforth substantially control us. Similarly, the words I write scaffold the words I may write.

The example of the lesson plan again shows how it can be misleading to focus on the most easily identified object (physical or otherwise) in an assembly. The technology that matters is that object plus the orchestrated assembly of which it is a part, including the soft technologies added by its participants. A computer, for instance, is rarely of interest as a technology in itself unless you are buying or making one. There are indefinitely many ends to which it might be put, but that is at least as true of the transistors and screws inside it and, equally, depends on what we add, notably including the relationships between the parts in the assembly. Computers are interesting because of what they lack - the gaps that must be filled - that are a result of the vast numbers of adjacent possibles they enable. And, because they can play so many roles, when pre-programmed for roles like automating a factory or powering a sales terminal, to their end users they can be much harder than nails (which are actually quite soft technologies).

It is easy to treat an obvious technology as a synecdoche for both things it is a part of, and for things of which it is constructed. An LMS, say, is not one thing but, at least, billions, different to every person that uses it. Some of these are obvious: the tangible components of which it is made, say, or the course areas that may be created within it. Similarly, a single course instance might contain a discussion environment, a lesson authoring tool, a grading tool, and much else, of varying value and plasticity in different situations, not to mention courses and lessons, and be used within a framework of organizational regulations and, above all, pedagogies with which 
it is assembled, and not just those of the ostensive teacher. Your LMS is not my LMS, and your course is not my course, but we blithely use the same term to stand in for everything and anything in which it plays a role. From there it is all too easy to treat it as one technology rather than the multitude it can become (or become a part of). This is a mistake. Something as complicated as an LMS may contain many technologies that are counter to those we wish to apply ourselves, or inadequate to the tasks we set (Dron, 2007;Dron, 2014), as well as many that are not, and its defaults can greatly influence how its coparticipants behave (Dron, 2006). It is, though, just one set of assemblies in countless further assemblies. For all its flaws, almost any LMS may be orchestrated into assemblies that soften its default behaviours. Through assembly with counter technologies (such as hyperlinks to elsewhere, or instructions to bypass it, or simply through the ways we interact with it or interpret its meaning in a given context) many of its weaknesses can be mitigated. However, the softer we make it, the more effort, skill, and decision-making is needed for all concerned. It is difficult to leave the established path. The softer components are always more affected by the harder than vice versa and the harder and less flexible the technology becomes, the more influential is its role. It is thus not surprising that, in countless ways, courses built within an LMS tend to resemble one another in as many ways as they differ.

\section{The distributed teacher}

From the collaboration of design teams and course groups to the cooperative processes of building a Wikipedia article or contributing to an open source project, we often deliberately participate in and through technologies with others. However, there are many other far less 
deliberate and more ubiquitous ways to be co-participants. For example, a teacher may orchestrate many phenomena in order to teach, from hard organization of content to soft facilitation of interaction, but the educational technology assembly is not complete without the further (soft) orchestration of phenomena by the learners themselves that actually leads to learning, and that will usually at least partly differ from what the teacher intends. Learners always learn a lot more than they are taught (including attitudes, ways of learning, values, and so on) and integrate what they have learned with their existing knowledge in always unique, never static ways. The teacher and student are part of the same assembly, each playing their role in the overall machine, but neither is in absolute control of it and neither provides all the processes, methods, and techniques needed to make it work. The educational technology that matters is a gestalt, enacted by many people, tools, and structures.

Beyond those formally identified as teachers and students, there are countless other coparticipants in almost all educational activities, the vast majority of which make a material contribution to the teaching process. Even in the hardest, teacher-controlled classroom, classmates, timetablers, writers, editors, illustrators of textbooks, creators of regulations, designers of classrooms, whiteboard manufacturers, developers and managers of LMSs, lab technicians, and indefinitely many others can play significant teaching roles, orchestrating parts of the assembly that teachers and finally students in turn orchestrate to fit their needs. These are just the obvious visible tips of the iceberg.

True autodidacts do not exist. We might orchestrate some parts of the assembly (our choice and sequence of resources, for example) but, whether reading books (being taught by authors), 
watching videos (being taught by their makers) or simply reading an instruction manual or help file, self-directed learning is almost always anything but: we may choose some of the tools, and our own interpretations will always be unique, but we are not the only participants. Even without such obvious teachers, the learner usually applies many methods and techniques that they have been taught by others, from use of language to approaches to memorization, often learned far in the past, typically from many teachers. When we claim to teach ourselves, we are only referring to one obvious part of the assembly - a particular kind of structuring and/or support role - not to the entire orchestration. Conversely, truly dependent learners do not exist either. Even in the most tightly controlled behaviourist classroom, learners are constantly making choices, such as whether to pay attention or thinking about how what they are doing relates to other things they care about. Usually, they are doing much more than that. Indeed, there is a strong case to be made that the more they orchestrate themselves, the more effective, meaningful, persistent, and useful the learning will be. This is the basic assumption behind the vast majority of constructivist learning theories, all complexivist learning models (Davis \& Sumara, 2007), and quite a lot of cognitivist theories of learning.

Many further coparticipants may contribute to the orchestration. Learning may be affected by events in learners' personal lives, news stories, social media shares, television shows, conversations, and so on, any of which may play a significant teaching role, making learning more meaningful, connected, or personal. When learners have left the classroom, such phenomena continue to teach, and they are often used by learners to elaborate, modify, amplify, or sometimes to overturn what has been taught in a classroom, typically invisibly to the teacher, sometimes days, weeks, months or even years after the original teaching event. 
Learning cannot be neatly partitioned into the time or place in which deliberate teaching occurs, and is never static.

More generally, all technologies teach. The cognitive effects of technologies are most obvious in tools like language, art, theory, or pedagogy, but all inventions participate in our cognition, from doors to laws (Gibson, 1977). As McLuhan (1992, p.3) put it, "each of man's artefacts is in fact a kind of word, a metaphor that translates experience from one form into another." Further, as Clark (2008) argues, it makes little sense to treat cognition as something that occurs solely in our brains. We are not just users of technologies, but they are literally a part of how we think, extensions of our minds. Our cognition is deeply distributed, mediated through the tools and artefacts we share, from language to dishcloths. This is the essence of what makes us smart, as individuals and as a species (Norman, 1993). We embed the thought and creativity that went into orchestrating phenomena in the resultant technologies into our own, making use of the phenomena they in turn provide, reinterpreting them, leading to ever greater sophistication. More often than not, we benefit from the refinements and successive rejections of weaker technologies that have occurred, sometimes over millennia, as well as the countertechnologies that have reduced their ill effects. This is the evolutionary ratchet of civilization, the fundamental dynamic of technology, and what makes complex thought possible in the first place. Our intelligence itself is deeply distributed (Bloom, 2000) and our minds are made, in important ways, from 'gadgets' to think with that we have learned from those who came before us (Heyes, 2018), from whom we learned not just the 'grist' with which to think, but the 'mill' through which thought occurs. This gestalt is soft, situated, deeply distributed, complex and emergent. 


\section{Some example applications of the coparticipation model}

The consequences of viewing education as a coparticipative technological process are profound. The following set of examples illustrates how this perspective sheds light on some commonplace phenomena, but is by no means exhaustive.

\subsection{No-significant difference}

Many studies and metastudies comparing learning with 'technology' (normally meaning anything electronic) and without, have (on average) revealed little or no significant difference in outcomes (e.g. Pei \& Wu, 2019; Means et al, 2013; Russell, 1999; Chen, Lambert, \& Guidry, 2010; Tamim et al, 2011). This is unsurprising. Investigations of the effects of (say) computers on learning are meaningless because there are potentially infinite ways that computers can be used, infinite phenomena with which they can be assembled (including those provided by other technologies such as pedagogies), and a vast range of software and hardware they can contain. So, unless there were some unequivocally general pernicious effects (computers emitted some hitherto undiscovered radiation that wiped memories, say) then the assembly, and its orchestration matter far more, especially the layers of counter-technologies used to address their shortcomings, as well as the adjacent possibles chosen to be useful within the unique context of use. Moreover, even if some truly universal harmful effects were to be discovered, they could be fixed: computers are inventions, not unchanging natural phenomena. As they change, we change, the surrounding systems change, and yesterday's discoveries 
Choice of technology does matter a lot, because of 1 ) how it affects other technologies in the assembly, 2) the adjacent possibles it provides, and 3) the avenues it closes. However, it is the orchestrated assembly that teaches, not any one component of it. Any effectiveness or otherwise of the assembly is a measure of emergent teaching skill among all the distributed teachers involved. This is equally true of methods of teaching (pedagogies) or learning designs. If assembled with poor techniques or tools, normally effective pedagogies may achieve little or no benefit, or may even be counter-productive. Conversely if a teacher uses poor pedagogies (or even fails to turn up) it may sometimes enable (though not cause) great learning, because of all the other teachers involved in the process. Equally, a mediocre pedagogy performed well may succeed better than a good pedagogy performed poorly. For instance, Andrews et al (2011) observe that 'good' active learning pedagogies that had been shown to be highly effective in prior research studies were, when used by inexperienced and poorly informed teachers, actually less effective (according to the hard measures used) than the didactic full-

frontal teaching methods they replaced. But, of course, plenty of learning happened in all these cases, even if it were not what was intended by the designated teacher, and plenty of other teachers, from students themselves to textbook authors, were coparticipants in the process.

\subsection{The 2-sigma problem}

The importance of the overall assembly again figures when considering Bloom's (1983) 2-Sigma problem: that no teaching method has consistently reached the level of effectiveness (by some measures) of one-to-one or small group tuition, and not much has come close. Regardless of any concerns we might have about how effectiveness is measured, this is an unfair contest. 
Personal tuition is not a method but a situation in which any methods or other tools can be used. Thanks to the ease with which the tutor can diagnose and respond to students' needs and interests, these are likely to be well adapted to what students need at any moment. Even if a method or other tool were found to match personal tuition then tutors could simply add it to their toolbox and thus always stay ahead. Bloom's challenge cannot be met because it pits one technology against any and all technologies. It does, though, draw attention to the value of dialogue and close monitoring of learning and teaching effectiveness, which is highly correlated with success (Hattie, 2013). Again, this is not a method, but a situation.

\subsection{Bad things done well, and good things done badly}

Regardless of the average benefits of personal tuition, all bets would be off if the tutor were incompetent. Whether softer or harder, some technologies are better designed, or more fit for purpose, than others. There is an indefinitely large amount of orchestration, including idiosyncratic technique, that we must add to fill in the gaps of a soft technology like a pedagogical method, so the opportunities for enacting it well or badly are far greater than for a hard technology that always behaves in the same way.

Softer pedagogies like active learning, problem- or inquiry-based learning, and other loosely framed methods, are much more dependent on the skill of the teacher than harder methods such as direct instruction or behaviourist drill and practice. Measured by hard, well-defined outcomes (at best a poor caricature of part of the actual outcomes), the average success rates for softer pedagogies are therefore likely to be lower than well-proven harder pedagogies, because teachers are, on average, average. This is indeed, on average, what is found (De 
Bruyckere et al, 2015; Hattie, 2013; Andrews et al, 2011). Softer pedagogies are excellent for brilliant, experienced teachers who can fill their gaps creatively and compassionately; otherwise prebuilt well-proven harder methods are a safer bet because they perform some of the work. That said, all pedagogies are at least somewhat soft. There are very few methods or tools that cannot be used well, in the right assembly, and virtually none that cannot be used badly.

Extremely bad methods, or even none at all (from a formal perspective) can sometimes lead to effective learning, because the person identified as the teacher is only ever one of many teachers in any learning transaction. Others - especially the learners but also countless other technology makers from timetablers to legislators - may fill the gaps the teacher leaves.

\subsection{The implausibility of learning styles}

There are many reasons to reject theories that people have innate learning styles and that teaching to those styles will improve learning, the most obvious of which being the almost total absence of reliable evidence to support any of them (Husmann \& O'Loughlin, 2019; Riener \& Willingham, 2010; Pashler, McDaniel, Rohrer, \& Bjork, 2008a; Derribo \& Howard, 2007; Coffield, Moseley, Hall, \& Ecclestone, 2004; Hattie, 2013; De Bruyckere, Kirschner, \& Hulshof, 2015). This is not surprising, for the same reasons that studies find no significant difference between the outcomes of online and in-person learning. There will invariably be many other aspects of the assembly, especially the skill of a teacher to teach to a style, that, at least en masse, are far more significant than methodical alignment with a learning style. You cannot simply, say, remove printed words from a learning resource to accommodate visual learners: 
the entire orchestration has to change, and the way this is done will typically affect learning far more than the style that it accommodates.

A deeper problem for learning styles, though, is that methods of learning are soft technologies, that can be enacted with greater or lesser skill. There may be many reasons for developing an early preference for some methods but, once acquired, we are likely to preferentially practice them until we become better at them, because we tend to repeat things that we believe to work. We hone our technique. Being-taught habits may therefore appear to be innate and/or preferred styles of learning. Unfortunately, most of what we learn outside educational institutions does not come neatly packaged to suit a particular learning style, so it does learners a disservice to reinforce one identified style at the expense of others. Though lacking credibility, learning style theories may yet have some value in a learning design process as reminders that there are many possible strategies for learning. Technology is not applied science, and a theory does not require scientific validity to be useful.

\subsection{A singular lack of replication studies}

Because technologies are critical components of every educational experience, participating in an extraordinarily complex web of interdependent parts, in always novel ways that depend heavily on technique, enacted by countless participants it is unsurprising that - regardless of how much we have learned about learning and other phenomena that are part of the orchestration - reductive approaches to studying methods and tools of teaching have resulted in very little improvement in teaching overall, despite hundreds of thousands of attempts over many decades. It is also why Makel \& Plucker (2014) found that only $0.13 \%$ of studies in top 
journals were replication studies, mostly performed by the original researchers. Replication studies can work for extremely hard educational technologies applied in a rigidly consistent context - for example, to examine changes to test results brought about by different exam questions or processes - but these can only prove that the technology works as intended, not how it works, why it works, whether it is a good idea in the first place, nor whether it would work in even a slightly different context. Even the smallest of differences can matter: a teacher's random expletive or a bad cold can change an entire learning experience. Pedagogies are always soft technologies, dependent on skillful technique at least as much as method, of all the coparticipants. Combinatorial complexity makes things worse. Sometimes the complexity can be subtractive. For instance, high structure and high dialogue can both support effective distance education (Moore, 1993) but not together (Saba \& Shearer, 2004; Dron, 2007). Similarly, animation and text are great teaching tools, but not at once (Clark \& Meyer, 2011). Sometimes the complexity can be additive. Lectures are a terrible way to impart factual or conceptual knowledge (Laurillard, 1993) but few of us have never learned anything important as a result of one, so something must sometimes make them work. As Hattie (2013, pp. 34-35) rightly observes in a conclusion drawn from over 8000 metastudies, "nearly everything works", sometimes, and nothing works consistently. Many more subtle examples than this may surface in any learning transaction. The behaviour of a complex assembly is not predictable from a subset of its parts: knowing about pistons cannot predict a car. While, for a subset of pistondriven vehicles, some generalizations might be made about differences in behaviour due to type, size, and so on, such generalizations are useless when applied to electric or turbine 
vehicles. A car, though, is a very much harder and vastly much simpler technology, with far clearer and more unambiguously measurable success criteria and boundaries, than education.

Each act of teaching is fundamentally irreducible, bound by a virtual infinity of path dependencies and ever unfolding adjacent possibles, the effects of any of which may combine with, compete with, or interact with the effects of any of the rest, sometimes hours, days, weeks, or even decades after the event. The effects of education are almost certainly orders of magnitude more complex and harder to predict than the weather (Davis \& Sumara, 2006). The best reductive research in the field is no more (and no less) valuable than a good story.

\subsection{How is it, then, that some teachers consistently succeed more than others?}

Just as anyone can provide a reasonably reliable forecast of what the weather will be like in five minutes from now, so, too, for learning. Being human, and having evolved to understand other humans, we may respond intelligently and imaginatively, as long as we can sufficiently well

observe how people are learning, and how they are responding to our teaching - conditions that are the default in one-to-one tutoring - or we can imagine those effects, as I am doing now as I write this. This is not science, and it is anything but deductive or reductive. Like all technological inventions - and hence all of education - it is generative and inductive, a process of imaginative synthesis, on the part of all co-participants, especially including the learner.

Knowing more teaching methods is good because it increases the range of components that might creatively be used in an assembly: there are more adjacent possibles to choose from. Good methods matter, too, in the same way that good musical instruments matter to 
musicians: they embody the skills and ingenuity of the many people who contributed to their design and manufacture. The higher the quality, the more effectively they can contribute to our own orchestrations. However, a good instrument does not entail good music, nor vice versa. Just as a talented musician can often make great music with a poor instrument or a limited range of techniques, a great teacher can achieve much with a very limited range of methods or tools, and there is no correlation at all between the number of technologies used and success in learning. It is far more important to develop technique: to practice, to experiment, to study, and to become reflective practitioners, aware of what we do, what effects it has, and how learners are learning. As Hattie (2013) puts it, teaching and learning need to be made visible. And we must do it with feeling and empathy: caring for the subject, for learning, and for the learner are non-negotiable starting points for success. Only then can we select appropriate tools and methods, and apply skill and creativity to orchestrate them well.

\section{Conclusion}

Education is, primarily, not a process of instilling skills and facts, but of preparing human beings to live, work, and play with other humans in society. It is as fundamentally human as art and, just as it would make little sense to build a machine to make art (interesting though it is to try, and fascinating though the questions it raises about the nature and value of art may be), it makes little sense to build a machine to educate. Just as machines can extend and enable what an artist can create, so can machines support the educational process, but it is not the machine itself that achieves this. It is the ways that the machine is orchestrated by humans, with humans, and for humans that makes it educational. 
The hard methods, tools, and structures of education do matter a great deal. However, they have no value at all without how we creatively and responsively orchestrate them, fuelled by passion for the subject and process, and compassion for our coparticipants. It is pointless to research educational technologies unless we examine the orchestrations contributed by at least most of their coparticipants. Each orchestration is and must be unique, a story that we can learn from and integrate into our own assemblies, but that cannot predict the outcomes of doing so.

It follows that the purpose of education it not just to develop hard, measurable skills or literacies, but to cultivate the soft, creative, adaptable, ever-evolving skills to assemble them in new, useful, and meaningful ways, to be better than we are, to contribute more and gain more from our communities and environments. Though much satisfaction may be had from perfecting hard skills and playing our roles correctly, for the most part we do so in order to better perform soft tasks. We are all coparticipants in this deeply human, highly distributed educational machine, not just users but - necessarily - both creators and parts of its ever unfolding form.

Being parts of machines is part of what it means to be human, and being part-human is part of what it means to be a machine. If we can better understand how the machines work then, as coparticipants in them, we can make each one a thing of beauty and value rather than a vehicle of oppression. The mechanical can be and often is an essential part of the spontaneous, the creative, and the divine. Paintbrushes - when combined with artist, canvas and paint - are machines, too and, as William Carlos Williams (1969) puts it, a poem is a " machine made out of 
words." Educational technologies, from pedagogies to LMSs to assessment tools, should similarly combine to inspire, to help us to become better people, to be more than we are, to be happier, and (perhaps) more valuable members of our cultures and communities. This paper has only scratched the surface of the implications of a technology coparticipation perspective on educational research and practice but, I hope, it has provided enough to encourage further analysis and study.

\section{References}

Andrews, T. M., Leonard, M. J., Colgrove, C. A., \& Kalinowski, S. T. (2011). Active Learning Not Associated with Student Learning in a Random Sample of College Biology Courses. CBE-Life Sciences Education, 10(4), 394-405. doi:10.1187/cbe.11-07-0061

Aristotle, \& Whalley, G. (1997). Aristotle's Poetics: Translated and with a Commentary by George Whalley (G. Whalley, Trans.). Montreal: MQUP

Arthur, W. B. (2009). The Nature of Technology: what it is and how it evolves (Kindle ed.). New York, USA: Free Press.

Baldwin, J., \& Brand, S. (1978). Soft-tech. New York: Penguin.

Bijker, W. E., Hughes, T. P., \& Pinch, T. J. (Eds.). (1989). The Social Construction of Technological Systems. Cambridge, Mass.: MIT Press. 
Bloom, B. S. (1984). The 2 Sigma Problem: The Search for Methods of Group Instruction as Effective as One-to-One Tutoring. Educational Researcher, 13(6), 4-16. Retrieved from $\underline{\text { http://www.jstor.org/stable/1175554 }}$

Bloom, H. (2000). Global Brain: the evolution of mass mind. Toronto, Canada: Wiley.

Boden, M. (1995). Creativity and unpredictability. Stanford Humanities Review, 4(2), 123-139. Retrieved from http://portal.acm.org/citation.cfm?id=212171\&CFID=34973622\&CFTOKEN=46572978

Bonk, C. J., \& Kim, K.-J. (2005). Future directions of blended learning in Higher Education and Workplace Learning Settings. In C. J. Bonk \& C. R. Graham (Eds.), Handbook of blended learning: Global Perspectives, local designs (pp. 550-558). San Francisco: Pfeiffer Publishing.

Boyd, G. M. (1996). Emancipative educational technology. Canadian Journal of Educational Communication, 25, 179-186.

Brand, S. (2000). Clock Of The Long Now: Time And Responsibility: The Ideas Behind The World's Slowest Computer (Kindle ed.). Basic Books.

Brand, S. (1997). How buildings learn. London: Phoenix Illustrated.

Changizi, M. (2013). Harnessed: How Language and Music Mimicked Nature and Transformed Ape to Man. BenBella Books.

Chen, P.-S. D., Lambert, A. D., \& Guidry, K. R. (2010). Engaging online learners: The impact of Web-based learning technology on college student engagement. Computers \& Education, 
54(4), 1222-1232. Retrieved from

http://www.sciencedirect.com/science/article/pii/S0360131509003285

Clark, A. (2008). Supersizing the Mind: Embodiment, Action, and Cognitive Extension: Embodiment, Action, and Cognitive Extension. Oxford University Press.

Clark, R. C., \& Mayer, R. E. (2011). e-Learning and the Science of Instruction: Proven Guidelines for Consumers and Designers of Multimedia Learning (3rd ed.). Pfeifer.

Coffield, F., Moseley, D., Hall, E., \& Ecclestone, K. (2004). Learning styles and pedagogy in post-16 learning: A systematic and critical review. 041543).

Cooley, M. (1987). Architect or Bee? : The Human Price of Technology. London: The Hogarth Press.

Daniel, J., Kanwar, A., \& Uvalić-Trumbić, S. (2009). Breaking higher education’s iron triangle: Access, cost, and quality. Change: The Magazine of Higher Learning, 41(2), 30-35.

Davis, B., \& Sumara, D. J. (2006). Complexity and Education: Inquiries Into Learning, Teaching, and Research. Lawrence Erlbaum Associates.

De Bruyckere, P., Kirschner, P. A., \& Hulshof, C. D. (2015). Urban myths about learning and education. Academic Press.

Derribo, M. H., \& Howard, K. (2007). Advice about the use of learning styles: A major myth in education. Journal of college reading and learning, 37, 2. 
Dewey, J. (1916). Democracy and Education. New York: Macmillan. Retrieved from. Retrieved May 21, 2001, from the World Wide Web:

http://www.ilt.columbia.edu/projects/digitexts/dewey/d_e/contents.html

Dillenbourg, P., \& Jermann, P. (2010). Technology for Classroom Orchestration New Science of Learning: Cognition, Computers and Collaboration in Education., 525-552.

doi:10.1007/978-1-4419-5716-0_26

Dron, J. (2006). Any color you like, as long as it's Blackboard ${ }^{\circledR}$. Proceedings from E-Learn 2006, Hawaii.

Dron, J. (2007). Control and Constraint in E-Learning: Choosing when to Choose. Hershey, PA: Idea Group International. doi:10.4018/978-1-59904-390-6

Dron, J. (2013). Soft is hard and hard is easy: learning technologies and social media.Form@re, 13(1), 32-43. Retrieved from http://www.fupress.net/index.php/formare/article/view/12613

Dron, J., \& Anderson, T. (2014). Teaching crowds: Learning \& Social Media. Athabasca: AU Press. Retrieved from http://teachingcrowds.ca

Dubos, R. (1969). American Academy of Allergy 25th anniversary series: The spaceship earth. Journal of Allergy, 44(1), 1-9.

Franklin, U. M. (1999). The Real World of Technology (Kindle ed.). Concord ON: House of Anansi Press.

Franklin, U. M. (2014). Ursula Franklin Speaks: Thoughts and Afterthoughts. MQUP.

Freire, P. (1972). Pedagogy of the Oppressed. (M. B. Ramos, Trans.). New York: Herder. 
Frisch, M. (1994). Homo Faber. Houghton Mifflin Harcourt.

Gibson, J. J. (1977). The Theory of Affordances. In R. Shaw \& J. Bransford (Eds.), Perceiving, Acting, and Knowing: Toward an Ecological Psychology (pp. 67-82). Hillsdale, NJ: Lawrence Erlbaum.

Goel, A. K., \& Polepeddi, L. (2016). Jill Watson: A virtual teaching assistant for online education.

Haraway, D. (2013). Simians, cyborgs, and women: The reinvention of nature. Routledge.

Hattie, J. (2013). Visible Learning: A Synthesis of Over 800 Meta-Analyses Relating to Achievement. Taylor \& Francis.

Heyes, C. (2018). Cognitive Gadgets: The Cultural Evolution of Thinking. Harvard University Press.

Huntrods, R., \& Dron, J. (2017). Engagement with Robots: Building a Social, Self-paced, Online Robotics Course. Proceedings from E-Learn: World Conference on E-Learning in Corporate, Government, Healthcare, and Higher Education, 2017, 365-372.

Husmann, P. R., \& O’Loughlin, V. D. (2019). Another Nail in the Coffin for Learning Styles? Disparities among Undergraduate Anatomy Students' Study Strategies, Class Performance, and Reported VARK Learning Styles. Anatomical Sciences Education, 12(1), 6-19. doi:10.1002/ase. 1777

Kauffman, S. (2000). Investigations (Kindle ed.). New York: Oxford University Press. 
Kauffman, S. (2008). Reinventing the Sacred: A New View of Science, Reason and Religion. Philadelphia, PA: Basic Books.

Kauffman, S. A. (2019). A World Beyond Physics: The Emergence and Evolution of Life. Oxford University Press.

Kelly, K. (2010). What Technology Wants (Kindle ed.). New York: Viking.

Lakhana, A. (2014). What is Educational Technology? An Inquiry into the Meaning, Use, and Reciprocity of Technology,. Canadian Journal of Learning and Technology / La revue canadienne de l,Äôaprentissage et de la technologie; Vol 40, No 3 (2014). Retrieved from http://www.cjlt.ca/index.php/cjlt/article/view/823/399

Laurillard, D. (1993). Rethinking University Teaching- a framework for the effective use of educational technology. London: Routledge.

Makel, M. C., \& Plucker, J. A. (2014). Facts Are More Important Than Novelty: Replication in the Education Sciences. Educational Researcher, 43(6), 304-316. doi:10.3102/0013189X14545513

McDonough, E. F., \& Kahn, K. B. (1996). Using 'hard' and 'soft' technologies for global new product development. $R \& D$ Management, 26(3), 241-253. doi:10.1111/j.14679310.1996.tb00959.x

McLuhan, M., \& McLuhan, E. (1992). Laws of Media: The New Science. Toronto, Canada: University of Toronto Press. 
Means, B., Toyama, Y., Murphy, R., \& Baki, M. (2013). The effectiveness of online and blended learning: A meta-analysis of the empirical literature. Teachers College Record, 115(3), 147.

Moore, M. G. (1993). Theory of transactional distance. In D. Keegan (Ed.), Theoretical principles of distance education (pp. 23-38). London: Routledge.

Norman, D. A. (1993). Things that make us smart: defending human attributes in the age of the machine. Cambridge, MA: Perseus Publishing.

Nye, D. E. (2006). Technology Matters: Questions to Live With. Cambridge, Massachusetts: MIT Press.

O’Neill, R.V., DeAngelis, D.L, Waide, J. B., \& Allen, T. F. H. (1986). A Hierarchical Concept of Ecosystems. Princeton University Press.

Olson, J. K. (2013). The purposes of schooling and the nature of technology: The end of education. In The nature of technology (pp. 217-248). Brill Sense.

Page, S. E. (2011). Diversity and complexity. Princeton University Press.

Pashler, H., McDaniel, M., Rohrer, D., \& Bjork, R. (2008). Learning styles: Concepts and evidence. Psychological science in the public interest, 9(3), 105-119.

Pei, L., \& Wu, H. (2019). Does online learning work better than offline learning in undergraduate medical education? A systematic review and meta-analysis. Medical Education Online, 24(1), 1666538. doi:10.1080/10872981.2019.1666538 
Plato. (360 BCE). The Phaedrus (B. Jowett, Trans.). Project Gutenberg. Retrieved from http://www.gutenberg.org/files/1636/1636-h/1636-h.htm

Polanyi, M. (1966). The tacit dimension. London: Routledge.

Postman, N. (2011). The End of Education: Redefining the Value of School. Knopf Doubleday Publishing Group.

Read, L. E. (1958). I, pencil.

Rheingold, H. (2012). Mind Amplifier: Can Our Digital Tools Make Us Smarter? (Kindle ed.). TED Books.

Ridley, M. (2010). The Rational Optimist: how prosperity evolves. London, UK: HarperCollins e-books.

Riener, C., \& Willingham, D. (2010). The Myth of Learning Styles. Change: The Magazine of Higher Learning Change: The Magazine of Higher Learning, 42(5), 32-35. doi:doi: $10.1080 / 00091383.2010 .503139$

Russell, T. L. (1999). The No Significant Difference Phenomenon: As Reported in 355 Research Reports, Summaries and Papers. North Carolina: North Carolina State University.

Saba, F., \& Shearer, R. L. (1994). Verifying key theoretical concepts in a dynamic model of distance education. The American Journal of Distance Education, 8(1), 36-59.

Sarid, A. (2018). A theory of education. Cambridge Journal of Education, 48(4), 479-494. doi:10.1080/0305764X.2017.1356267 
Technology. (n.d.). In Oxford University Press, Oxford Dictionary of English. Retrieved 11 Dec. 2012, from http:// www.oxfordreference.com

Tamim, R. M., Bernard, R. M., Borokhovski, E., Abrami, P. C., \& Schmid, R. F. (2011). What Forty Years of Research Says About the Impact of Technology on Learning. Review of Educational Research, 81(1), 4-28. doi:10.3102/0034654310393361

Turkle, S., \& Papert, S. (1992). Epistemological Pluralism and the Revaluation of the Concrete. Journal of Mathematical Behavior, 11(1), 3-33. Retrieved from http://papert.org/articles/EpistemologicalPluralism.html

Williams, W. C. (1969). The Wedge. In Selected essays of William Carlos Williams (p. 256). NY: New Directions.

Wilson, E. O. (2012). The social conquest of earth (Kindle ed.). New York: Liveright Pub. Corporation. 